\title{
Effects of the storage of breast milk at different temperatures on total antioxidant capacity, total oxidant status, and paraoxonase-1 level
}

\author{
Murat Konak ${ }^{1}$, Murat Minici², Nuriye Tarakçi ${ }^{3}$, Hüseyin Altunhan ${ }^{3}$, Aysun Toker ${ }^{4}$, \\ Rahmi Örs ${ }^{3}$ \\ ${ }_{1}^{1}$ Division of Neonatology, Department of Pediatrics, Selçuk University, Selçuklu Medical Faculty; Departments of \\ ${ }^{2}$ Pediatrics, ${ }^{3}$ Neonatology and ${ }^{4}$ Biochemistry, Meram Medical Faculty, Necmettin Erbakan University, Konya, Turkey, \\ E-mail:drmkonak@hotmail.com \\ Received: 3rd September 2018, Accepted: 16th October 2018
}

SUMMARY: Konak M, Minici M, Tarakçı N, Altunhan H, Toker A, Örs R. Effects of the storage of breast milk at different temperatures on total antioxidant capacity, total oxidant status, and paraoxonase-1 level. Turk J Pediatr 2019; 61: 1-6.

Breast milk is a well-balanced ideal nutritional source with high bioavailability for infants. As being a fresh, biological and dynamic product, changes in the breast milk during these storage periods have been the subject of ongoing research. This study aims to evaluate total antioxidant capacity (TAC), total oxidant status (TOS), and paraoxonase-1 (PON-1) levels of fresh and freezestored breast milk. Ten cc of breast milk was obtained from the mothers as the days between 10 and 15 in the morning within a 1-hour period. TAC, TOS, and PON-1 levels were evaluated in the fresh breast milk. Collected breast milk samples were divided into two groups for storage at $-20^{\circ} \mathrm{C}$ or $-80^{\circ} \mathrm{C}$. Stored samples were tested for TAC, TOS, and PON-1 levels after 72 hours. The highest TAC level was detected in fresh breast milk $(\mathrm{p}<0.05)$. The TOS levels of fresh breast milk showed a statistically significant reduction in rate after storage. The TOS levels at $-20^{\circ} \mathrm{C}$ and $-80^{\circ} \mathrm{C}$ were significantly lower at $-80^{\circ} \mathrm{C}(\mathrm{p}<0.05)$. Our study results show that oxidant and antioxidant activities are at the maximum level in the fresh breast milk. In terms of antioxidant status the effect of freezing temperatures hasn't been determined. We conclude that it is more convenient to store the breast milk at $-80^{\circ} \mathrm{C}$ than to store at $-20^{\circ} \mathrm{C}$ in terms of preserving the storage TOS level.

Key words: stored breast milk, oxidant status, antioxidant status, paraoxonase-1.

Breast milk is a well-balanced ideal nutritional source with high bioavailability for infants, which supports healthy growth and development due to the compounds and nutrients contained. ${ }^{1}$ However, storage of breast milk is needed in conditions where available breast milk exceeds the requirements of an infant as is the case in premature newborns, or when administration to the infant is not possible after collection of breast milk due to inability to perform enteral feeding in the intensive care unit setting. As being a fresh, biological and dynamic product, changes in the breast milk during these storage periods have been the subject of ongoing research. ${ }^{2,3}$

More than a hundred diseases have been associated with free oxygen radicals. In studies performed, decrease in the antioxidant and increase in the oxidant levels have been demonstrated to enhance the risk of development of neonatal diseases as intraventricular hemorrhage, retinopathy of prematurity (ROP), necrotizing enterocolitis (NEC) and bronchopulmonary dysplasia (BPD) 4 Newborns, especially preterm infant have been shown to be lacking sufficient antioxidant 
capacity against oxygen radicals in the first days of life. ${ }^{4}$ Breast milk has protective features for newborns also due to its antioxidant characteristics. However, changes can occur in antioxidant features of the breast milk while keeping and storing. These changes can be demonstrated by the measurement of total antioxidant capacity (TAC), total oxidant status (TOS) and level of PON-1.5-7

Paraoxonase-1 (PON-1), a sensitive and specific endogenous antioxidant enzyme, is produced in hepatocytes in the liver. Local chromatin paraoxonase (PON) in region q21-22 of chromosome 7 consists of three members called PON-1, PON-2 and PON-3. It has been observed that PON1 has an antioxidant effect against lipid peroxidation caused by free radicals on cell membranes and lipoproteins. ${ }^{8,9}$

In the present study, we aimed to evaluate the changes in TAC, TOS and PON-1 levels in breast milk samples collected from the mothers and stored either at $-20^{\circ} \mathrm{C}$ or $-80^{\circ} \mathrm{C}$ and determining ideal storage conditions becomes important due to these changes.

\section{Material and Methods}

The study included breast milk samples collected from 35 healthy mothers, who delivered their babies between 38 and 42 weeks of gestation The study was approved by the Institutional Ethics Committee (2013/323).

Neonates with severe respiratory distress syndrome, premature rupture of membranes (PROM), severe congenital malformation, congenital metabolic disease, severe sepsis, pathological jaundice, cyanotic congenital heart disease, perinatal asphyxia, renal and hepatic failure, newborns receiving antioxidant therapy, patients on dialysis, patients with maternal history of alcohol, smoker/passive smoker and drug use or antioxidant therapy, and patients with maternal history of diabetes were excluded.

A written informed consent was obtained from each participant. An attention was paid to ensure that samples were obtained between days 10 and 15 after birth, and breast milk was collected in the morning. All mother expressed their own breast milk for collection. A 10-cc sample of breast milk was collected into a polypropylene tube and kept away from sunlight. All samples were collected within 1 hour and sent to the biochemistry laboratory.

Breast milk samples were divided into three groups. The samples in the first group (fresh breast milk) were immediately analyzed. The samples in the other two groups were stored at either $-20^{\circ} \mathrm{C}$ or $-80^{\circ} \mathrm{C}$ for 72 hours before analysis.

After breast milk samples were centrifuged at $3500 \mathrm{rpm}$ for $10 \mathrm{~min}$, a $1 \mathrm{cc}$ clear middle layer was transferred to an Eppendorf tube for micro-centrifugation. TAC, TOS and PON-1 levels were immediately determined in one tube. Other tubes were placed in a refrigerator for storage at $-20^{\circ}$ or $-80^{\circ} \mathrm{C}$. After storage for 72 hours, tubes were thawed with a Bain marie method by keeping at $35-38^{\circ} \mathrm{C}$ for 15 min. After the samples were thawed, TAC, TOS and PON-1 levels were studied.

The TAC, TOS, and PON-1 levels in these samples were analyzed collectively at one time at the Central Biochemistry Laboratory of Institutional.

\section{Serum paraoxonase measurement}

Paraoxon was used as a substrate in the measurement of PON-1 activity and the absorbance of the color with hydrolysis of paraoxon was read at $412 \mathrm{~nm}$ and $37^{\circ} \mathrm{C} .{ }^{10}$ PON-1 activity was measured as the baseline activity. The results were expressed as U/L. ${ }^{10}$

\section{Measurement of serum total antioxidant capacity}

TAC was determined by an automated method based on the reduction of 2,2-azino-bis (3-ethylbenzthiazoline-6-sulfonic acid) (ABTS) radical with a characteristic color to a colorless reduced form in the sample. ${ }^{11}$ The results were expressed as Trolox equivalents/L. ${ }^{11}$

\section{Measurement of serum total oxidant status}

TOS was determined using an automated measurement method. ${ }^{12}$ The oxidants within the sample converts ferrous ion-o-dianisidine complex to ferric ion. In an acidic environment, ferric ion forms a colored complex with xylenol orange. The intensity of color measured with spectrophotometric method is related to a total amount of oxidant molecules. The measurement was calibrated with hydrogen peroxide $\left(\mathrm{H}_{2} \mathrm{O}_{2}\right)$ and the results were expressed as micromolar 
$\mathrm{H}_{2} \mathrm{O}_{2}$ equivalent in liters ( $\mu \mathrm{mol} \mathrm{H} 2 \mathrm{O} 2$ equiv./L).

\section{Statistical Analysis}

Statistical analysis was performed using the SPSS version 21.0 (IBM Corp., Armonk, NY, USA). The Kolmogorov-Smirnov and Shapiro-Wilk normality tests were carried out to determine whether the data were appropriate for normal distribution. Descriptive data were presented in mean \pm standard deviation and abnormally distributed data were expressed in median (min-max) values. The Friedman analysis was used to compare groups of dependent numerical variables without normal distribution. For statistically significant outcomes, Wilcoxon test was used to compare groups within themselves. A $p$ value of $<0.05$ was considered statistically significant.

\section{Results}

Demographic features of the mothers and infants included in the study are shown in Table I.

The median TAC level was $1.65 \mathrm{mmol} /$ trolox equiv./L in fresh breast milk, $0.55 \mathrm{mmol} /$ trolox equiv./L in samples stored at $-20^{\circ} \mathrm{C}$, and $0.65 \mathrm{mmol} /$ trolox equiv. $/ \mathrm{L}$ in samples stored at $-80^{\circ} \mathrm{C}$. Comparison of two storage conditions with fresh breast milk showed that antioxidant levels were significantly lower in stored samples compared to the fresh breast milk $(p<0.05)$. However, although anitoxidant levels were higher in samples stored at $-80^{\circ} \mathrm{C}$, the difference was not statistically significant $(\mathrm{p}=0.846)$ (Table II).

The median TOS level was $79.75 \mu \mathrm{mol} \mathrm{H} 2 \mathrm{O} 2$ equiv. /L in fresh breast milk, $18.7 \mu \mathrm{mol}$ $\mathrm{H} 2 \mathrm{O} 2$ equiv. / $\mathrm{L}$ in samples stored at $-20^{\circ} \mathrm{C}$, and $14.30 \mu \mathrm{mol} \mathrm{H} 2 \mathrm{O} 2$ equiv. /L in samples stored at $-80^{\circ} \mathrm{C}$. TOS levels in fresh breast milk samples were significantly higher compared to the two storage conditions $(p<0.05)$. The analysis of TOS levels in samples stored at $-20^{\circ} \mathrm{C}$ and $-80^{\circ} \mathrm{C}$ showed that total oxidant status was significantly lower in fresh breast milk samples $(p=0.001, p 1=0.045, p 2=0.001$, p3 $=0.024$ ) (Table II).

The median PON-1 level was $0.35 \mathrm{U} / \mathrm{L}$ in fresh breast milk, $0.0 \mathrm{U} / \mathrm{L}$ in samples stored at $-20^{\circ} \mathrm{C}$, and $0.0 \mathrm{U} / \mathrm{L}$ in samples stored at $-80^{\circ} \mathrm{C}$. Although paraoxonase activity in samples stored at $-20^{\circ} \mathrm{C}$ was lower compared to the fresh breast milk samples, the difference was not statistically significant $(p=0.217)$ (Table II).

\section{Discussion}

Breast milk is a unique, irreplaceable food source for all infants. ${ }^{1}$ In some cases, breast milk needs to be stored for periods exceeding allowed time for storage in room temperature. The question of whether or not storage changes oxidant-antioxidant features of breast milk has been of particular concern although this would not interfere with breastfeeding of the infant. The use of frozen and stored breast milk is particularly more common in the feeding of premature newborns ${ }^{13}$. Breast milk that may have been influenced by storage conditions predisposes these infants to diseases such as necrotizing enterocolitis, bronchopulmonary dysplasia, and retinopathy of premature. ${ }^{14-18}$

In the present study mothers with terms infants were selected for inclusion as the breast milk of mothers with premature newborns show differences to that of mothers with term infants. Breast milk was expressed on the same day and hour of the day. Collected milk was kept away from sunlight because light can induce oxidant activity. 7,19

It has been shown that the oxidative properties

Table I. Age, Weight and Gestational Week of Babies in the Study Group ( $n=35)$.

\begin{tabular}{|c|c|c|c|c|}
\hline Parameters & & mean \pm SD & Minimum & Maximum \\
\hline Age (year) & & $29.3 \pm 5.9$ & 19 & 43 \\
\hline Gestational week & & $38.6 \pm 0.7$ & 38 & 40 \\
\hline Weight (g) & & $3100.0 \pm 367.8$ & 2500 & 4000 \\
\hline \multirow[t]{2}{*}{ Sex } & Male & $21(60.0 \%)$ & & \\
\hline & Female & $14(40.0 \%)$ & & \\
\hline
\end{tabular}




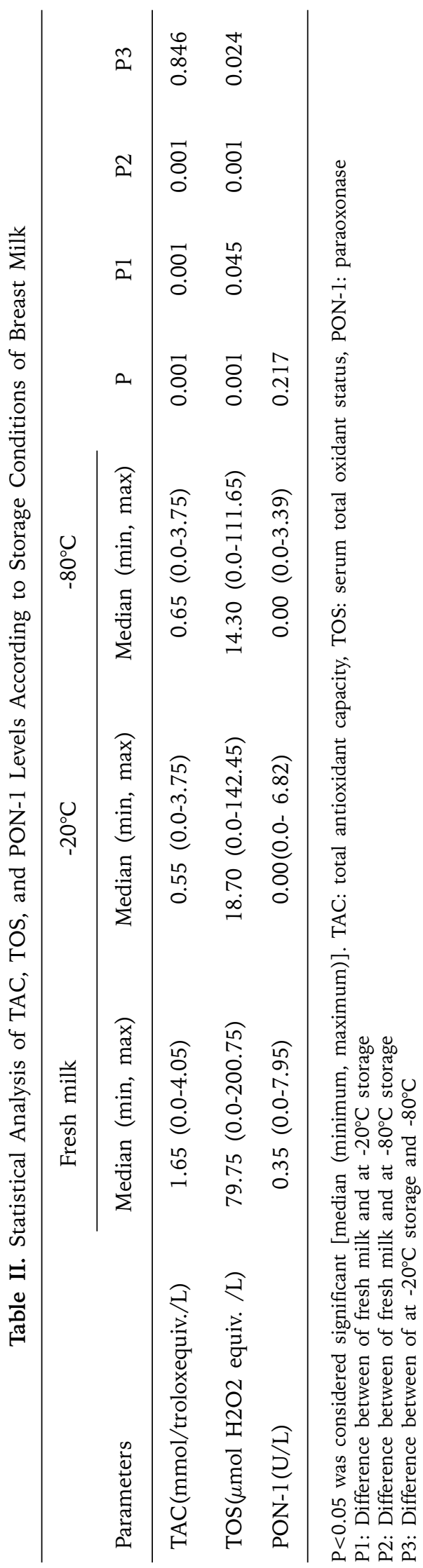

of breast milk change during long-term freezing and storage. 7,20 The present study evaluated antioxidant, oxidant and paraoxonase levels in transitional fresh breast milk collected between days 10 and 15 and stored at $-20^{\circ} \mathrm{C}$ and $-80^{\circ} \mathrm{C}$ for 72 hours and so changes that occurred during short-time freezing could also be evaluated. The level of antioxidants in fresh breast milk was shown to be significantly decreased after freezing and storage for 72 hours $(p<0.05)$. This finding was consistent with the literature. ${ }^{20}$ Fresh Breast milk possesses the highest level of antioxidant properties. However, our literature search was unable to find any study that compared the paraoxonase level. When evaluated with respect to TAC, the decrease in antioxidant capacity was found to be lower in samples stored at $-80^{\circ} \mathrm{C}$ than the samples stored at $-20^{\circ} \mathrm{C}$, while comparison of PON-1 levels showed higher paraoxonase activity in samples stored at $-20^{\circ} \mathrm{C}$ (Table II). However, there was no statistically significant difference when the two temperature conditions were compared with each other. Silvestre et al. ${ }^{20}$ evaluated antioxidant capacity with the measurement of Glutathione Peroxidase Activity (GPx) levels and they reported higher antioxidant capacity when the samples were stored at $-80^{\circ} \mathrm{C}$ for less than 30 days. After 60 days, the GPx activity was minimal and the activity of GPx exhibited no significant differences between the 2 temperatures.

The comparison of TOS levels showed that fresh breast milk possessed the highest level of oxidant capacity and samples stored at $-80^{\circ} \mathrm{C}$ had the lowest levels, and the difference was statistically significant $(\mathrm{p}<0.05)$. The studies have emphasized that free fatty acids produced by the breakdown of lipid fractions by the enzyme lipase was responsible for the oxidant capacity of the breast milk. As fresh Breast milk possesses the highest lipase activity, this could explain higher TOS in the breast milk. The activity of this enzyme is sustained at $-20^{\circ} \mathrm{C}$; however, when the temperature is further declined to $-80^{\circ} \mathrm{C}$, this enzyme would be inactive causing lower oxidant capacity. ${ }^{20-24}$. Silvester et al. ${ }^{20}$ found that according to the results obtained with lipid peroxidation markers, breast milk remains stable during 30 days when freeze stored at both $-20^{\circ} \mathrm{C}$ and $-80^{\circ} \mathrm{C}$. However, when frozen storage was 
prolonged to 60 days at both temperatures was the stable state deteriorated and the oxidant capacity increased. In our study we evaluated TAC and TOS after 72 hours, we did not evaluate the effect of long-term freezing.

Another study showed that freezing breast milk reduced antioxidant capacity, keeping breast milk in the refrigerator had a smaller impact than freezing, and storage for more than 48 hours reduced antioxidant capacity. ${ }^{25}$ The aforementioned study also showed that storing breast milk at $+4^{\circ} \mathrm{C}$ for 48 hours reduced antioxidant capacity, compared to the fresh breast milk, although the difference was not statistically significant. According to the results of the present study, the highest TAC levels were observed in fresh breast milk. TAC was remarkably reduced in breast milk samples stored at $-20^{\circ} \mathrm{C}$ and $-80^{\circ} \mathrm{C}$ for 72 hours and the difference was statistically significant.

Another study that compared breast milk and formula showed higher levels of lipid peroxidation products in breast milk, compared to formula. Samples were stored at $-20^{\circ} \mathrm{C}$ to compare antioxidant levels and the decrease in antioxidant capacity in breast milk was found to be statistically significant; however, despite this decrease, antioxidant levels were higher in breast milk, compared to formula. They suggested that the decrease in antioxidant capacity in breast milk was associated with the presence of lipoprotein lipase activity at $-20^{\circ} \mathrm{C}$ and increased production of free fatty acids. ${ }^{22}$

Another study which evaluated antioxidant and oxidant levels in fresh breast milk in comparison to breast milk stored at $-80^{\circ} \mathrm{C}$ for 2 months showed that antioxidant and oxidant levels were not reduced in colostrum. The level of antioxidant status was remarkably lower in transitional and mature Breast milk and the statistical difference was strongly significant. No statistical or proportional decline was observed in the oxidant status. ${ }^{26}$ The study by Akdağ et al. ${ }^{27}$ found a decrease in antioxidant capacity without any decrease in oxidant capacity, and the authors concluded that breast milk stored at $-80^{\circ} \mathrm{C}$ could be recommended in premature newborns. However, a decrease in the antioxidant capacity in frozen breast milk together with a statistically significant decrease in oxidant capacity is an important finding to suggest that the use of frozen breast milk is safe.

In a study that evaluated total antioxidant capacity, malondialdehyde, and $\mathrm{pH}$ values in the breast milk of 30 healthy mothers at 25,36 , 48 and 72 hours, $\mathrm{pH}$ was shown to decrease gradually at the beginning and antioxidant status decreased after the first 24 hours. They suggested that, considering the antioxidant status, expressed milk must be consumed in less than 24 hours if it has to be stored.28 Due to the fact that all samples were stored for 72 hours in the present study, no comment was made regarding the duration of storage.

The major limitation of our study was that we excluded neonates smaller than 38 weeks and that the sample size was small.

In conclusion, based on our study results, we suggest that storage at $-80^{\circ} \mathrm{C}$ would be appropriate in terms of TOS, if the breast milk needs to be stored before consumption. However, further large-scale studies are needed to determine how this storage temperature would affect other molecules in the breast milk.

\section{REFERENCES}

1. American Academy of Pediatrics. Breastfeeding and the use of human milk. Pediatrics 2012; 129: e827-e841.

2. Kim MH, Shim KS, Yi DY, et al. Macronutrient Analysis of Human Milk according to Storage and Processing in Korean Mother. Pediatr Gastroenterol Hepatol Nutr 2019; 22: 262-269.

3. Orbach R, Mandel D, Mangel L, Marom R, Lubetzky $\mathrm{R}$. The effect of deep freezing on human milk macronutrients content. Breastfeed Med 2019; 14: 172-176.

4. Perrone S, Bracciali C, Di Virgilio N, Buonocore G Oxygen use in neonatal care: A two-edged sword. Front Pediatr 2017; 4: 143.

5. Annagür A, Örs R, Altunhan $\mathrm{H}$, et al. Total antioxidant and total oxidant states, and serum paraoxonase 1 in neonatal sepsis. Pediatr Int 2015; 57: 608-613.

6. Konak M, Tarakci N, Altunhan H, Annagür A, Toker A, Örs R. Total antioxidant, total oxidant and serum paraoxonase levels according to lipid administration method in parenterally fed premature infants. J Matern Fetal Neonatal Med 2017; 30: 1734-1738.

7. Aksu T, Atalay Y, Türkyılmaz C, et al. The effects of breast milk storage and freezing procedure on interleukine-10 levels and total antioxidant activity. J Matern Fetal Neonatal Med 2015; 28: 1799-1802.

8. Schrader C, Ernst IM, Sinnecker H, Soukup ST, Kulling SE, Rimbach G. Genistein as a potential inducer of the anti-atherogenic enzyme paraoxonase-1: studies in cultured hepatocytes in vitro and in rat liver in vivo. J Cell Mol Med 2012; 16: 2331-2341. 
9. Draganov DI, La Du BN. Pharmacogenetics of paraoxonases: A brief review. Naunyn-Schmiedebergs Arch Pharmacol 2004; 369:78-88.

10. Eckerson HW, Wyte CM, La Du BN. The human serum paraoxonase/arylesterase polymorphism. Am J Hum Genet 1983; 35: 1126-1138.

11. Erel O. A novel automated direct measurement method for total antioxidant capacity using a new generation, more stable ABTS radical cation. Clin Biochem 2004; 37: $277-285$.

12. Erel O. A new automated colorimetric method for measuring total oxidant status. Clin Biochem 2005; 38: 1103-1111.

13. Schlotterer HR, Perrin MT. Effects of refrigerated and frozen storage on holder-pasteurized donor human milk: A systematic review. Breastfeed Med 2018; 13: 465-472.

14. Friel JK, Martin SM, Langdon M, Herzberg GR, Buettner GR. Milk from mothers of both premature and fullterm infants provides better antioxidant protection than does infant formula. Pediatr Res 2002; 51: 612-618.

15. Korchazhkina O, Jones E, Czauderna M, Spencer SA. Effect of exclusive formula or breast milk feeding on oxidative stress in healthy preterm infants. Arch Dis Child 2006; 91: 327-329.

16. Hamosh M. Protective functions of proteins and lipids in human milk. Biol Neonate 1998; 74: 163-176.

17. Lawrence RA. Storage of human milk and the influence of procedures on immunological components of human milk. Acta Paediatr Suppl 1999; 88: 14-18.

18. Ogundele MO. Effects of storage on the physicochemical and antibacterial properties of human milk. Br J Biomed Sci 2002; 59: 205-211.

19. Laborie S, Lavoie JC, Pineault M, Chessex P. Contribution of multivitamins, air, and light in the generation of peroxides in adult and neonatal parenteral nutrition solutions. Ann Pharmacother 2000; 34: 440445 .
20. Silvestre D, Miranda M, Muriach M, Almansa I, Jareño E, Romero FJ. Frozen breast milk at $-20^{\circ}$ degrees $\mathrm{C}$ and $-80^{\circ}$ degress C: A longitudinal study of glutathione peroxidase activity and malondialdehyde concentration. J Hum Lact 2010; 26: 35-41.

21. Friend BA, Shahani KM, Long CA, Vaughn LA. The effect of processing and storage on key enzymes, B vitamins, and lipids of mature human milk: I. Evaluation of fresh samples and effects of freezing and frozen storage. Pediatr Res 1983; 17: 61-64

22. Turoli D, Testolin G, Zanini R, Bellú R. Determination of oxidative status in breast and formula milk. Acta Paediatr 2004; 93: 1569-1574.

23. Bitman J, Wood DL, Mehta NR, Hamosh P, Hamosh M. Lipolysis of triglycerides of human milk during storage at low temperatures: A note of caution. J Pediatr Gastroenterol Nutr 1983; 2: 521-524.

24. Berkow SE, Freed LM, Hamosh M, et al. Lipases and lipids in human milk: Effect of freeze-thawing and storage. Pediatr Res 1984; 18: 1257-1262.

25. Hanna N, Ahmed K, Anwar M, Petrova A, Hiatt M, Hegyi T. Effect of storage on breast milk antioxidant activity. Arch Dis Child Fetal Neonatal Ed 2004; 89: F518-F520.

26. Sari FN, Akdağ A, Dizdar EA, et al. Antioxidant capacity of fresh and stored breast milk: Is $-80^{\circ} \mathrm{C}$ optimal temperature for freeze storage? J Matern Fetal Neonatal Med 2012; 25: 777-782.

27. Akdag A, Nur Sari F, Dizdar EA, et al. Storage at$80^{\circ} \mathrm{C}$ preserves the antioxidant capacity of preterm human milk. J Clin Lab Anal 2014; 28: 415-418.

28. Miranda M, Gormaz M, Romero FJ, Silvestre D. Stability of the antioxidant capacity and $\mathrm{pH}$ of human milk refrigerated for 72 hours: Longitudinal study. Nutr Hosp 2011; 26: 722-728. 